\author{
Dietrich Schlenzka \\ Timo Laine \\ Teija Lund
}

\title{
Computer-assisted spine surgery
}

Received: 2 September 1999

Accepted: 2 September 1999
D. Schlenzka $(\bowtie) \cdot$ T. Laine $\cdot$ T. Lund ORTON Orthopedic Hospital, Invalid Foundation, Tenholantie 10, FIN-00280 Helsinki, Finland e-mail: Dietrich.schlenzka@invalidisaatio.fi, Tel.: +358-9-47486264, Fax: +358-9-2418415

\begin{abstract}
Computer assistance has been shown to improve significantly the accuracy and safety of pedicle screw insertion under clinical conditions. The technique of image-guided navigation is described in this article, based on the authors' clinical experience of over 4 years. The value of navigation systems for preoperative planning is discussed. Clinical results of the application of this new method in the cervical, thoracic, and lumbosacral spine as well as the iliosacral joints are presented by
\end{abstract}

\begin{abstract}
means of the authors' own studies and reports from the literature. Pros and cons of computer guidance are discussed. The authors predict computer navigation will be used in percutaneous and minimally invasive procedures in the near future.
\end{abstract}

Key words Image-guided spine surgery $\cdot$ Computer navigation . Cervical spine - Thoracic spine . Lumbar spine - Iliosacral joint . Pedicle screws

\section{Introduction}

Computer-assisted techniques were introduced into clinical practice in spine surgery at the beginning of the 1990s. The development of computerized intraoperative guiding systems was stimulated by several developments:

1. Modern imaging modalities, in particular computed tomography (CT) and magnetic resonance imaging (MRI), allow the surgeon to plan the operations in detail. However, until recently, it was not possible to transfer the preoperative plan directly to the operation situation. Thus, a significant amount of the preoperative image and planning data remained unused.

2. Surgical procedures and implants have become increasingly complex. Patients as well as spine surgeons demand new methods to improve safety and diminish the risk of complications.

3 . Further progress in minimally invasive spine surgery requires the ability to guide instruments with high accuracy.

There are three groups of computer navigation systems:
1. Passive navigators are guiding systems that provide the surgeon with real-time data about the exact position of the instrument in the surgical field without interfering with the surgeon's action.

2. Active navigators, or robots, perform a preplanned surgical action without interference of the surgeon.

3. Semi-active navigators allow the surgeon to perform the action within preoperatively defined limits. If the surgeon goes beyond the limits the system stops the action.

Computer navigation systems are based on the principle of stereotaxis. Stereotactic operation techniques have been used in brain surgery since the beginning of the century to guide the surgical instrument into a certain target area. The basic components of the original stereotactic set-up are the surgical object (e.g., a brain tumor), the virtual object (an image of the brain from a brain atlas) and a frame (navigator) fixed to the skull of the patient for guidance of the surgical instrument according to the coordinates extrapolated from the brain image. Since a mechanical frame is used to guide the instrument, this technique is called "frame-based" stereotaxis. 
The new "frameless" concept has become possible due to developments in medical imaging and computer science. The exact coordinates of the surgical object can be defined in a three-dimensional (3D) CT data set of the region of interest. The instruments are used by the surgeon and navigated by a motion analysis system without any mechanical frame. Optical (infrared light), magnetic (electromagnetic field) or acoustic (ultrasound) signals are utilised to localise the position of the instrument in space $[2,7,17,23,24,27$, $28,36]$. Optoelectronic navigators working with infrared light emitting diodes (LEDs) are used in most clinical applications. They require more sophisticated equipment, but they have turned out to be very precise and reliable.

An alternative technique is based on individual templates generated preoperatively from CT scans of the patient $[30,32]$. This method works without any intraoperative computer equipment. It has been used in pelvic osteotomies. There are, however, no reports yet on its clinical application in spine surgery.

After successful use of frameless stereotaxis in the field of neurosurgery, optoelectronic systems were modified for use in spine operations. The optoelectronic navigation system for spine surgery consists of the following main components:

1. Instruments (Fig. 1) equipped with LEDs. The instruments including the LEDs are rigid bodies. They are precalibrated, i.e., the geometric parameters will have been measured and stored in the computer.

Fig. 1 Stereotactic instruments (pedicle awl, pedicle probe) equipped with light emitting diodes (Medivision, Oberdorf, Switzerland)

Fig. 2 Operation demonstration in a plastic spine model. The dynamic reference base (DRB) is fixed to the spinous process. The tip of the pedicle awl marks the screw entrance point

Fig. 3 Infrared camera system (Optotrak, Northern Digital, Waterloo, Canada) on a movable stand

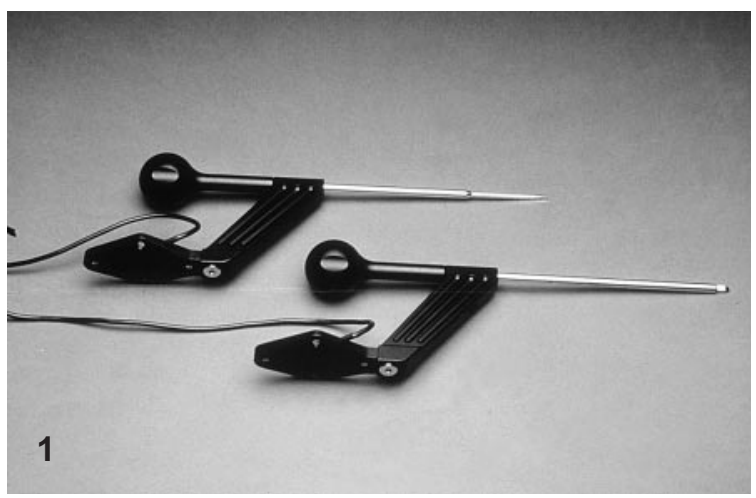

2. A dynamic reference base (DRB) also equipped with LEDs to be fixed to the surgical object (Fig. 2). This allows the system to follow the position of the surgical object in space and to compensate for movements caused by breathing of the patient or manipulations by the surgeon.

3. An infrared camera system (Fig. 3) that is able to recognise the LEDs of the instruments and of the DRB in the operative field with high precision and to give their coordinates to the central computer.

4. The central control unit and monitor.

In navigation systems based on ultrasound or electromagnetic field, neither camera nor LEDs is necessary. Instead one needs either an ultrasound source and a receiver or a coil for producing the magnetic field.

\section{Technique of optoelectronic navigation}

At the ORTON Orthopedic Hospital of the Invalid Foundation in Helsinki, an optoelectronic navigation system has been used in spine surgery since 1995 . The system was developed at the Maurice E. Müller Institute of Biomechanics of the University of Bern in co-operation with the Orthopedic University Hospital at the Inselspital [27, 28, 33]. The improved model (SurgiGATE Spine 2.1, Medivision, Oberdorf, Switzerland) has been available in Helsinki since April 1998.

\section{Preoperative planning}

Preoperatively, a CT study of the whole area of the spine to be operated on is obtained. The image data are transferred to the central control unit of the navigation system. The quality of the CT scans is of paramount importance. Using the planning module of the system, the spine is re-
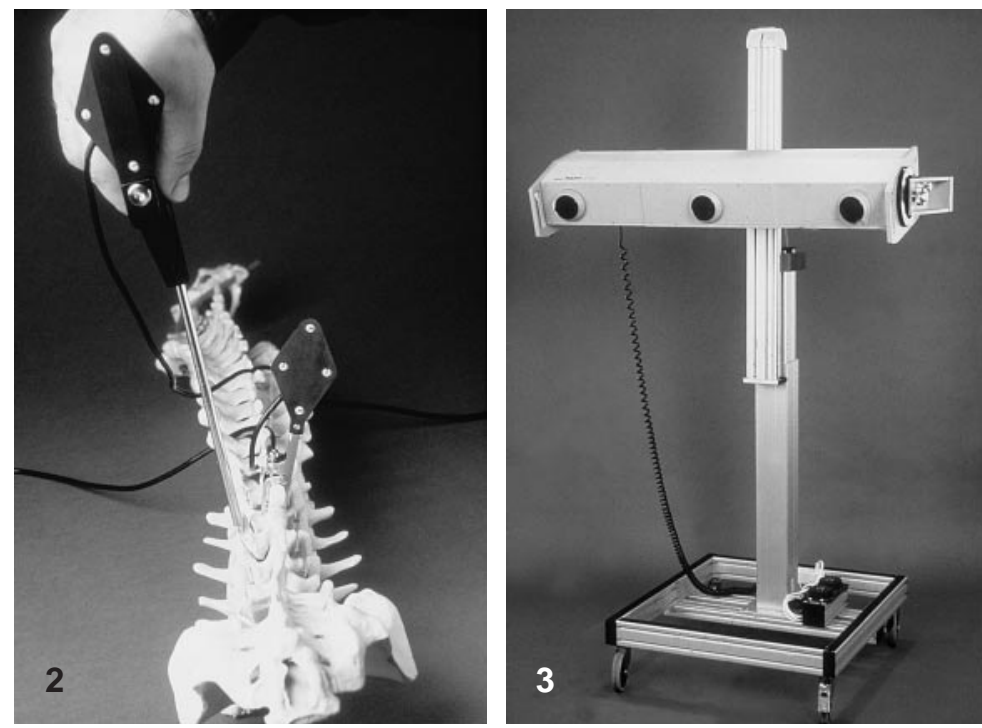
constructed and displayed in anterior-posterior, lateral and frontal views as well as a 3D image. This gives the surgeon the opportunity to study the anatomy in detail and to plan the operative procedure (e.g., decompression, tumor resection). The coordinates of three to six intraoperatively identifiable anatomical landmarks of each vertebra to be instrumented are obtained for use in the matching procedure during the surgery. For pedicle screw insertion the optimal trajectory is defined for every single screw and stored in the computer, including screw length and diameter.

Intraoperative procedure

Surgical exposure of the posterior vertebral elements is performed according to conventional principles. Damage of the bony surfaces has to be strictly avoided.

The infrared camera is positioned at the caudal end of the operation table. The dynamic reference base is fixed to the vertebra to be instrumented. The system can be operated by the surgeon using a foot switch and a sterile virtual keyboard.

For the matching procedure, the preoperatively chosen anatomic landmarks are located in the patient's situs and digitized by the surgeon with a space pointer. Using a special algorithm, the computer then matches the "virtual world" of the CT image with the "real world" of the patient's anatomy. After this paired-point matching, a sur- face matching can be added to further improve the accuracy. For the surface matching the surgeon digitizes randomly 10 to 15 points at the surface of the vertebra. This procedure is of special value in patients with missing posterior vertebral elements after earlier surgery. An accuracy check, a crucial step in the procedure, is performed to verify the quality of the matching. The surgeon has to judge and to decide whether the matching accuracy is acceptable for safe navigation, by comparing the position of the instrument in the operative field with the displayed position of the instrument in the CT image on the monitor. If the accuracy is insufficient, the matching procedure has to be repeated.

There are two options for screw track preparation. In the guidance mode (Figs. 4, 5), preplanned trajectories are displayed on the monitor. The screw entry point is located with the pedicle awl according to the plan. The screw track is then prepared with the pedicle probe following the trajectory on the monitor. The depth of the instrument inside the vertebra is displayed in millimetres. In real-time mode the screw track is prepared without preplanned trajectories. The tip of the instrument is placed on the presumed screw entry point. The monitor picture shows the actual position of the instrument in axial, sagittal and orthogonal CT cuts as well as six orthogonal cuts through the longitudinal axis of the instrument at a distance of $4,8,10,12$, 18, and $40 \mathrm{~mm}$ from its tip (Fig. 6). This allows the surgeon to adjust the direction of the instrument to the patient's
Fig. 4 The surgeon follows the position of the instrument on the monitor

Fig. 5 Monitor picture of the guidance mode. The instrument (green) is at the planned entry point adjusted to the planned screw trajectory (red)

Fig. 6 Monitor picture of the real-time mode. The tip of the instrument (green) has reached the narrowest part of the pedicle at $15 \mathrm{~mm}$ depth
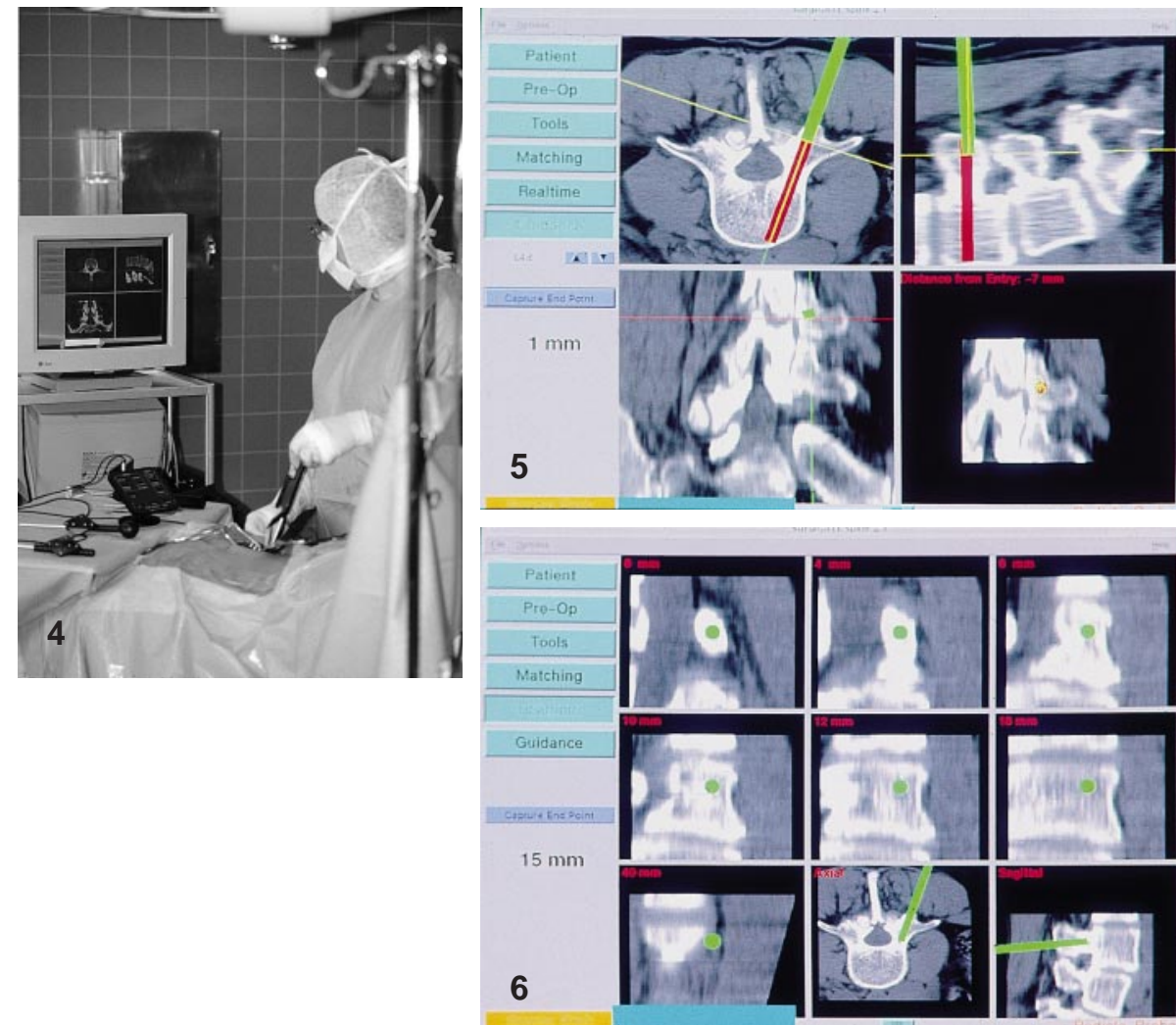
anatomy and to prepare a screw channel safely through the pedicle until the anterior cortex of the vertebra is reached. The depth of the track is displayed in millimetres, allowing the surgeon to choose a screw of appropriate length.

Ideally, a separate matching procedure should be performed for each vertebra to be instrumented. Clinical experience shows, however, that often the adjacent vertebra can be instrumented without a new matching, especially in degenerative spines with decreased segmental mobility.

\section{Clinical results}

\section{Thoracic and lumbar spine}

A prospective clinical trial was performed in 30 adult patients with degenerative or olisthetic problems to test the clinical applicability of the system [22, 33]. Postoperatively, pedicle screw position was judged by an independent radiologist using a sophisticated CT protocol including reformatted images perpendicular to the longitudinal axis of the pedicle [20]. Titanium screws were used to minimize postoperative imaging artefacts. Overall, 174 pedicle screws were implanted, of which 139 (79.9\%) were placed using the system. In the remaining 35 screws (20.1\%), computer assistance could not be used due to technical problems. Out of the 139 screws inserted with computer assistance, $133(95.7 \%)$ were positioned perfectly inside the pedicle. Six screws $(4.3 \%)$ perforated the lateral pedicle cortex: four by up to $2.0 \mathrm{~mm}$, and two by $2.1-4.0 \mathrm{~mm}$. Five out of the 35 screws (14.3\%) implanted by a conventional technique perforated the pedicle cortex: three by up to $2.0 \mathrm{~mm}$, one by $2.1-4 \mathrm{~mm}$, and one by $4.1-6 \mathrm{~mm}$. The location of the perforations was medial in three screws, lateral in one and caudal in one screw. A nerve root irritation was seen in one patient of the conventional group. It recovered after repositioning of the 4.1-6 mm medially misplaced screw. The difference in perforation rates between the computer-assisted and the conventional technique was statistically significant (chi-square test, $P=0.030$ ).

To further critically evaluate the results, a prospective randomized clinical trial comparing computer-assisted and conventional pedicle screw application was initiated in April 1998. Between April and November 1998, 46 patients were operated on at levels between T9 and S1 [19]. The pedicle perforation rate in screws implanted with computer guidance was $4.1 \%$ (4/98). With the conventional technique the rate was $15.9 \%(23 / 145)$. The difference is statistically significant (chi-square test, $P=0.004$ ). There is, however, not only a numeric difference in favor of the computer navigation group. As in the first study [22], there is also a qualitative difference. In the computer-assisted group, all four perforations were found to be located in the lateral pedicle cortex. In the conventional group, 14 out of 23 perforations were situated medially and five inferiorly, in potentially more dangerous areas. However, there were no neurologic complications. The final results of this study of 100 consecutive operations are currently under evaluation.

Other studies on clinical results using optoelectronic navigation systems in the region of the thoracic and lumbar spine were published by groups from Bern [34] and Grenoble [24, 25]. Schwarzenbach et al. [34] presented a prospective series of 162 pedicle screw insertions (between T11 and S2). Out of 150 screws inserted with adequate preoperative $\mathrm{CT}$ images feasible for computer navigation, 4 screws $(2.7 \%)$ perforated the pedicular cortex. Thirteen screws $(8.7 \%)$ were judged as "questionable" because of significant artefacts in the postoperative CT images. Merloz et al. [24] found $7.7 \%$ perforations of up to $1 \mathrm{~mm}$ out of 52 pedicle screws (between T10 and L5) in the treatment of vertebral fractures. In scoliosis operations (between T12 and L4) the same authors report a $14.3 \%$ perforation rate in 28 screws. More recently, in a comparative study [25] they judged 6 of 66 computer-navigated screws (9\%) as misplaced in comparison to 30 fo 66 misplaced screws (40\%) after the conventional implantation technique.

Kalfas et al. [17] reported on the insertion of 150 stainless steel pedicle screws in the region L1-S1 using an ultrasound-based navigation system. In postoperative CT images, they found "minimal" lateral pedicle cortex perforations in $8 \%$ and a "significant" lateral perforation without clinical relevance in one screw $(0.7 \%)$. Amiot et al. [2, 3] analyzed 292 pedicle screws (between T2 and S1) inserted using an electromagnetic navigation system. Cortex perforations of up to $2 \mathrm{~mm}$ were found in $5 \%$ of the screws in follow-up MR images. Putzier et al. [29] compared retrospectively the screw positions in 100 patients (70 thoracic screws, 474 lumbosacral screws) operated on by a conventional technique with 100 patients (112 thoracic screws, 508 lumbosacral screws) operated on using electromagnetic computer navigation. The follow-up was based on postoperative MR images. The perforation rate was $4.8 \%$ in the computer-assisted screws and $15.4 \%$ when a conventional screw insertion technique was used. Perforations of $2 \mathrm{~mm}$ and more were detected only in the conventional group. Ebmeier et al. [9] reported on the combined intraoperative use of a mobile CT scanner and an ultrasound navigator. In 13 patients 58 pedicle screws were inserted. No pedicle perforations were noted.

\section{Cervical spine}

There are reports on the successful clinical use of computer navigation in the cervical spine by Welch et al. [38], Foley et al. [10] and Bolger [5]. Welch et al. [38] reported on 11 cases including transoral odontoid resection, $\mathrm{C} 1-\mathrm{C} 2$ screw fixations, and tumor resections. The navigation system was used for preoperative planning of the procedures, in particular to decide the margins of the area to be re- 
sected, and for guiding of the instruments. No complications occurred. Foley et al. [10] used an optoelectronic system in 150 spine operations. There were thoracolumbar pedicle screw fixations, transarticular $\mathrm{C} 1-\mathrm{C} 2$ screw fixations, transoral odontoid resections, as well as tumor resections. In 24 patients they performed a computer-assisted posterior screw fixation of the lateral mass. Postoperative CT scans revealed exact screw positions in all cases.

Bolger [5] investigated the feasibility of computer navigation to assist $\mathrm{C} 1-\mathrm{C} 2$ screw fixation for atlanto-axial subluxation in 25 patients with rheumatoid arthritis and in two patients with $\mathrm{C} 2$ fractures. In four patients, preoperative CT scans revealed anatomic anomalies, excluding screw fixation of this region. Problems with intraoperative registration (matching) occurred in another patient. In the remaining 22 cases a successful $\mathrm{C} 1-\mathrm{C} 2$ fixation was performed.

Iliosacral joint

After positive experiences with the reliability and accuracy of the navigation system in the region of the thoracic and lumbar spine, we decided to extend its use to the iliosacral (SI) joint. Screw fixation of the SI joint involves a high risk of neural damage due to the complex anatomy of the region. Furthermore, it is difficult to get adequate intraoperative fluoroscopy images of this area for safe screw application. We performed unilateral SI joint fixations with three cannulated cancellous screws in two adult patients (Fig. 7). In a 14-year-old girl with a secondary scoliosis due to lumbosacral myelomeningocele, posterior instrumentation was fixed to the pelvis by bilateral iliosacral and iliac screws inserted with computer guidance. Postoperative CT images showed exact screw positioning according to the preoperative plan in all three patients. No neurologic complications occurred [21].

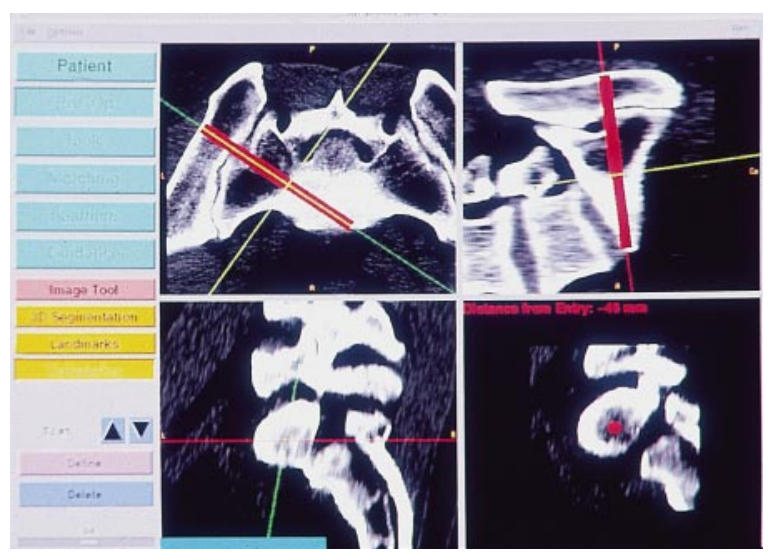

Fig. 7 Preplanned trajectory for an iliosacral screw, aiming at the upper anterior corner of S1
Jacob et al. [15] reported on 20 patients who underwent CT-guided percutaneous iliosacral screw fixation for sacral fractures. In cases where additional optoelectronic navigation was used, the application of the guide pins was successful at the first attempt. No complications related to the technique were seen.

\section{Computer navigation}

with an image intensifier (c-arm technique)

The navigation technique described above is based on a CT image as a virtual object. The so called c-arm technique works without a computer tomogram $[26,35]$. In this technique the c-arm equipped with LEDs and specially calibrated is connected to the computer of the navigation system. Two to three c-arm images (posterior-anterior, lateral, oblique) are obtained from the area of interest of the spine and stored in the computer. Then the c-arm is taken out of the operative field. Navigation is performed using LEDarmed stereotactic instruments, which are displayed in realtime in the stored fluoroscopy images at the monitor. This technique may be very useful in trauma cases. It includes the possibility of obtaining repeatedly actual images in case of instability of the surgical object. It is, however, not capable of displaying axial images of the spine.

\section{Discussion}

The introduction of CT image based computer guidance systems into spine surgery allows the surgeon for the first time to navigate an instrument inside the vertebra with the help of real-time 3D images. Several clinical studies have shown that this technique improves the accuracy and safety of pedicle screw insertion $[2,3,5,9,10,15,17,19,21$, $22,24,25,29,33,34,38]$. There are few studies on the reliability of those systems under clinical conditions. In our own study of 30 consecutive patients, problems occurred in 35 out of 174 pedicle screws [22]. They were due to hardware failure in the prototype instruments as well as matching problems. With growing experience (learning curve) and technical improvements these problems were overcome. According to Grange et al. [14] optoelectronic navigation systems are likely to be more precise if compared to electromagnetic navigators. Furthermore, optoelectronic systems are not affected by ferromagnetic influences in the environment. Clinical results with electromagnetic navigation published by Putzier et al. [29] are comparable to those achieved with optoelectronic guidance. The authors, however, do not provide data on the accuracy and reliability of the electromagnetic system itself.

Computer navigation can be relatively time consuming. This depends, however, on the individual situation. In the case of a straightforward pedicle screw insertion into an anatomically normal lumbar vertebra in an adult, the 
computer-assisted technique will take more time than the conventional. However, computer assistance will save time if the anatomy is complicated, as in the severely deformed spine or the iliosacral joint.

In our randomized study, mean insertion time per screw was significantly longer with computer assistance (9.5 min) than with the conventional technique $(5.2 \mathrm{~min})$. There was, however, no significant difference in the mean operation time between the two groups (184 vs $177 \mathrm{~min}$ ) [19].

\section{Limits of computer navigation}

The accuracy requirements for a procedure depends on the dimensions of the surgical object. Rampersaud et al. [31] calculated from a geometric model the allowable translational and rotational errors for safe pedicle screw insertion. The maximal allowable error ranged from $0.0 \mathrm{~mm} / 0.0^{\circ}$ at $\mathrm{T} 5$ to $3.8 \mathrm{~mm} / 22.7^{\circ}$ at $\mathrm{L} 5$. According to the literature, the accuracy of optoelectronic navigation systems is 1.0$1.7 \mathrm{~mm}[10,28]$. This depends on the slice thickness of the CT, the precision of the navigator, and the quality of the intraoperative matching. To our knowledge, no data have been published on the clinical accuracy of electromagnetic or ultrasound-based navigation systems.

Due to the patient's anatomy, it is sometimes impossible to use the ideal trajectory for the screw track. For instance, at the cranial end of a instrumentation/fusion, the intervertebral joints must be saved. Often, the ideal trajectory for pedicle screw insertion interferes with the facet joint. Thus, to avoid damaging the joint the surgeon has to deviate from the ideal route and to select a more lateral entry point for the screw. We think this might be the cause of the perforation of the lateral pedicle cortex that we have seen in clinical cases [19, 22, 33].

How safe is computer navigation?

Computer navigation is a safe method on condition that the user is familiar with the principles and the practical use of the navigation system. We strongly disagree with Carl et al. [7], who stated that navigation systems are only helpful for beginners in spine surgery, but of little value for experts in the field. Their opinion is disproven by several studies showing that even also in experienced hands the misplacement rate of pedicle screws is surprisingly high $[3,8,12,16,20,25,29,37,39]$. A passive navigation system is a sophisticated aiming device - not a robot. All decisions and actions are performed by the surgeon. The system does not limit the surgeon's action. A computer-guidance system does not relieve surgeons of the decision making - it only supports them in this process [4].

As in any other technique, there is a learning curve in computer surgery. Surgeons have to practise the use of the planning module, i.e., interpretation of unfamiliar CT image projections and identification of anatomic landmarks in the CT as well as in the operative field. Moreover, they have to learn to judge the quality of the accuracy check, in order to decide whether to proceed with the navigation process or to perform a new matching procedure. The navigation system is no substitute for profound training in spine surgery. The surgeon has to have the experience to recognize possible problems with the system and to perform the procedure with a conventional technique if necessary. Adequate training and critical awareness of the problems are the key for successful and safe use of navigation systems.

Do the benefits of computer navigation make up for the costs?

The question above is justified, and it cannot be answered merely by comparing percentages of pedicle cortex perforations. One has to go further and take into account the fact that computer navigation systems allow a totally new way of preoperative planning and effective utilization of image information. The spine surgeon can go through the whole data set of the CT study and analyze it from the surgical point of view, independently from the radiologist. Preoperative planning in computer-assisted spine surgery does not only mean definition of trajectories and landmarks. It means the planning of the whole procedure, i.e., the amount and localization of decompression, resection of a tumor, or simulation of an osteotomy. The practical value and the advantages of preoperative planning in computer surgery, with its close relationship to the patient's individual anatomy, is stressed by Welch et al. [38], Foley et al. [10], and Bolger [5]. A cost-benefit analysis should take into account that we are just at the beginning of this development. The applicability and safety of the system has been shown in pedicle screw application. The next step will be its use in minimally invasive or percutaneous procedures. Laboratory studies of several groups have already shown promising results for percutaneous translaminar, iliosacral, and transpedicular screw insertion $[6,11,13]$. The usefulness of image guidance for anterior cervical corpectomy [1] and anterior cervical foraminotomy [18] has also recently been demonstrated in cadaver studies.

\section{Conclusion}

The clinical use of computer navigation systems in spine surgery is a reality. Significant progress in accuracy and safety of open pedicle screw insertion has been achieved by means of this new technique. In addition, the quality of preoperative planning can be improved by optimal utilization of image data. Since the reliability of these systems has been proven in open operations, their use for minimally invasive or percutaneous procedures can be expected in the near future. 
References

1. Albert TJ, Klein GR, Vaccaro AR (1999) Image-guided anterior cervical corpectomy. A feasibility study. Spine $24: 826-830$

2. Amiot L-P, Labelle H, DeGuise JA, Sati M, Brodeur P, Rivard CH (1995) Computer-assisted pedicle screw fixation. Spine 20: 1208-1212

3. Amiot L-P, Lang K, Zippel H, Labelle H (1998) Comparative accuracy between conventional and computer-assisted pedicle screw installation. Abstract no. 68, 25th Annual Meeting of the International Society for the Study of the Lumbar Spine, Brussels, 9-13 June, 1998

4. Berlemann U, Langlotz F, Langlotz U, Nolte LP (1997) Computerassistierte Orthopädische Chirurgie (CAOS). Orthopäde 26:463-469

5. Bolger C (1999) Preliminary experience with computer assisted surgery for $\mathrm{C} 1 / \mathrm{C} 2$ transarticular screw placement. Computer Assisted Orthopedic Surgery, Fourth International Symposium, Davos, 17-19 March, 1999, Abstract Book, S 25

6. Byström S, Griessen R, Webb J, Becker G (1999) Percutaneous insertion of translaminar facet screws: a new technique in spine surgery. Computer Assisted Orthopedic Surgery, Fourth International Symposium, Davos, 17-19 March, 1999, Abstract Book, S 27

7. Carl AL, Khanuja HS, Sachs BL, Gatto CA, vom Lehn J, Vosburgh K, Schenck J, Lorensen W, Rohling K, Disler D (1997) In vitro simulation: early results of stereotaxy for pedicle screw placement. Spine 22:1160-1164

8. Castro WH, Halm H, Jerosch J, Malms J, Steinbeck J, Blasius S (1996) Accuracy of pedicle screw placement in lumbar vertebrae. Spine $21: 1320-1324$

9. Ebmeier K, Haberland N, Kalff RL (1999) Spinal navigation in combination with intraoperative computed tomography. Computer Assisted Orthopedic Surgery, Fourth International Symposium, Davos, 17-19 March, 1999, Abstract Book, S 24

10. Foley KT, Smith KR, Smith MM (1999) Frameless stereotactic guidance of cervical spine lateral mass screw placement. In: Nolte LP, Ganz R (eds) Computer assisted orthopedic surgery (CAOS). Hogrefe \& Huber, Seattle Toronto Bern, S 89-98

11. Gautier E, Bächler R (1999) Transcutaneous screw placement for sacroiliac joint fixation: a feasibility study. Computer Assisted Orthopedic Surgery, Fourth International Symposium, Davos, 17-19 March, 1999, Abstract Book, S 12
12. Gertzbein SD, Robbins SE (1990) Accuracy of pedicular screw placement in vivo. Spine $15: 11-14$

13. Glossop N, Hu R, Dix G, Behairy Y (1999) Percutaneous registration technique for image guided pedicle screw placement. Computer Assisted Orthopedic Surgery, Fourth International Symposium, Davos, 17-19 March, 1999, Abstract Book, S 25

14. Grange S, Bunker T, Cooper J, Waldhausen S (1999) Comparing electrooptical and electro-magnetic guidance in the preparation in minimal access surgical training environments. Computer Assisted Orthopedic Surgery, Fourth International Symposium, Davos, 17-19 March, 1999, Abstract Book, S 36

15. Jacob AL, Messmer P, Baumann B, Suhm N, Steinbrich W, Regazzoni P (1999) Interactive single-step navigation in iliosacral screw fixation of sacral fractures and fracture dislocations. In: Nolte LP, Ganz R (eds) Computer assisted orthopedic surgery (CAOS). Hogrefe \& Huber, Seattle Toronto Bern, S 147-152

16. Jerosch J, Malms J, Castro WH, Wagner R, Wiesner L (1992) Lagekontrolle von Pedikelschrauben nach instrumentierter dorsaler Fusion der Lendenwirbelsäule. Z Orthop 130:479-483

17. Kalfas IH, Kormos DW, Murphy MA, McKenzie RL, Barnett GH, Bell GR, Steiner CP, Trimble MB, Weisenberger JP (1995) Application of frameless stereotaxy to pedicle fixation of the spine. J Neurosurg $83: 641-647$

18. Klein GR, Ludwig SC, Vaccaro AR, Rushton SA, Lazar RD, Albert TJ (1999) The efficacy of using an imageguided Kerrison punch in performing an anterior cervical foraminotomy. An anatomical analysis. Spine 24:13581362

19. Laine T, Lund T, Ylikoski M, Schlenzka D, Lohikoski J (1999) Accuracy of pedicle screw insertion with and without computer assistance: a prospective randomised controlled clinical trial of 46 consecutive patients. International Society for the Study of the Lumbar Spine, 26th Meeting, Kona, Hawaii, June 21-25, 1999

20. Laine T, Mäkitalo K, Schlenzka D, Tallroth K, Poussa M, Alho A (1997) Accuracy of pedicle screw insertion: a prospective CT study in 30 low back patients. Eur Spine J 6:402-405

21. Laine T, Schlenzka D, Lund T (1999) Sacro-iliac screw fixation with computer assistance. Computer Assisted Orthopedic Surgery, Fourth International Symposium, Davos, 17-19 March, 1999, Abstract Book, S 12
22. Laine T, Schlenzka D, Mäkitalo K Tallroth K, Nolte L-P, Visarius H (1997) Improved accuracy of pedicle screw insertion with computer assisted surgery. Spine 22:1254-1258

23. Lavalleé S, Sautot P, Troccaz J, Cinquin P, Merloz P (1995) Computerassisted spine surgery: a technique for accurate transpedicular screw fixation using CT data and a 3-D optical localizer. J Image Guid Surg 1:65-73

24. Merloz P, Tonetti J, Pittet L, Coulomb M, Lavalleé S, Sautot P (1998) Pedicle screw placement using image guided techniques. Clin Orthop 354:39-48

25. Merloz P, Tonetti J, Eid A, Fontanel F, Lavallée S, Troccaz J, Cinquin P, Pittet L (1999) Pedicle screw placement using computer assisted technique. Computer Assisted Orthopedic Surgery, Fourth International Symposium, Davos, 17-19 March, 1999, Abstract Book, S 38

26. Nolte L-P, Slomszykowski MA, Strauss MJ, Hofstetter R, Schlenzka D, Laine T, Lund T (1998) A novel approach to computer aided spine surgery: X-ray fluoroscopy based surgical navigation. European Orthopaedic Research Society, Eigth Meeting, Amsterdam, 9 May, 1998

27. Nolte L-P, Zamorano L, Jiang Z, Wang Q, Langlotz F, Berleman U (1995) Image-guided insertion of transpedicular screws: A laboratory set-up. Spine 20 : 497-500

28. Nolte L-P, Zamorano L, Visarius $\mathrm{H}$, Berlemann U, Langlotz F, Arm E, Schwarzenbach O (1995) Clinical evaluation of a system for precision enhancement in spine surgery. Clin Biomech 10:293-303

29. Putzier M, Lang K, Zippel H (1999) Comparative results between conventional and computer-assisted pedicle screw insertion in the thoracic, lumbar, and sacral spine. Computer Assisted Orthopedic Surgery, Fourth International Symposium, Davos, 17-19 March, 1999, Abstract Book, S 26

30. Rademacher K, Portheine F, Anton M, Zimolong A, Kaspers G, Rau G, Staudte HW (1998) Computer assisted orthopaedic surgery with image based individual templates. Clin Orthop 354: 28-38

31. Rampersaud YR, Simon DA, Foley KT (1999) Application specific accuracy requirements for image guided spinal surgery. Computer Assisted Orthopedic Surgery, Fourth International Symposium, Davos, 17-19 March, 1999, Abstract Book, S 42 
32. Schkommodau E, Radermacher K, Zimolong A, Portheine F, Staudte HW, Rau G (1999) Individual templates for pedicle screw placement. Computer Assisted Orthopedic Surgery, Fourth International Symposium, Davos, 17-19 March, 1999, Abstract Book, S 23

33. Schlenzka D, Laine T (1999) Computer-assisted pedicle screw insertion. First clinical experience. In: Nolte LP, Ganz R (eds) Computer assisted orthopedic surgery (CAOS). Hogrefe \& Huber, Seattle Toronto Bern, S 99-103
34. Schwarzenbach O, Berleman U, Jost B, Visarius H, Arm E, Langlotz F, Nolte L-P, Ozdoba C (1997) Accuracy of computer-assisted pedicle screw placement. An in vivo computed tomography analysis. Spine 22:452-458

35. Slomczykoswski M, Hofstetter R, Strauss M, Bourquin Y, Sati M, Nolte LP (1999) Fluoroscopy-based surgical navigation. Concept and possible clinical applications. In: Nolte LP, Ganz R (eds) Computer assisted orthopedic surgery (CAOS). Hogrefe \& Huber, Seattle Toronto Bern, S 206-217

36. Visarius H, Berlemann U, Schwarzenbach O (1999) Concept and clinical aspects of computer-assisted spine surgery. In: Nolte LP, Ganz R (eds) Computer assisted orthopedic surgery (CAOS). Hogrefe \& Huber, Seattle Toronto Bern, S 81-88
37. Weinstein JN, Spratt KF, Spengler D, Brick C, Reid S (1988) Reliability and validity of roentgenogram based assessment and surgical factors on successful screw placement. Spine 13: 1012-1018

38. Welch WC, Subach BR, Pollack IF, Jacobs GB (1997) Frameless stereotactic guidance for surgery of the upper cervical spine. Neurosurgery 40:958-963

39. Wiesner L, Kothe R, Rüther W (1999) Anatomic evaluation of two different techniques for the percutaneous insertion of pedicle screws in the lumbar spine. Spine 24 : 1599-1603 